\title{
TOTAL DISLOCATION OF THE ILIUM
}

\author{
Report of a Case
}

\author{
W. B. Mackinnon and E. L. Lansdown, Winnipeg, Manitoba, Canada \\ From the Orthopedic Radiology and Departments, University of Manitoba
}

A girl aged thirteen years was admitted in a state of shock to the Arturo Grullion Children's Hospital, Santiago, Dominican Republic, where one of us (W. B. McK.) was seconded for work with Care Medico. The child had been picking coffee beans when there was a fall of rock: she slipped and fell down a hill, and was struck by loose rock which fell

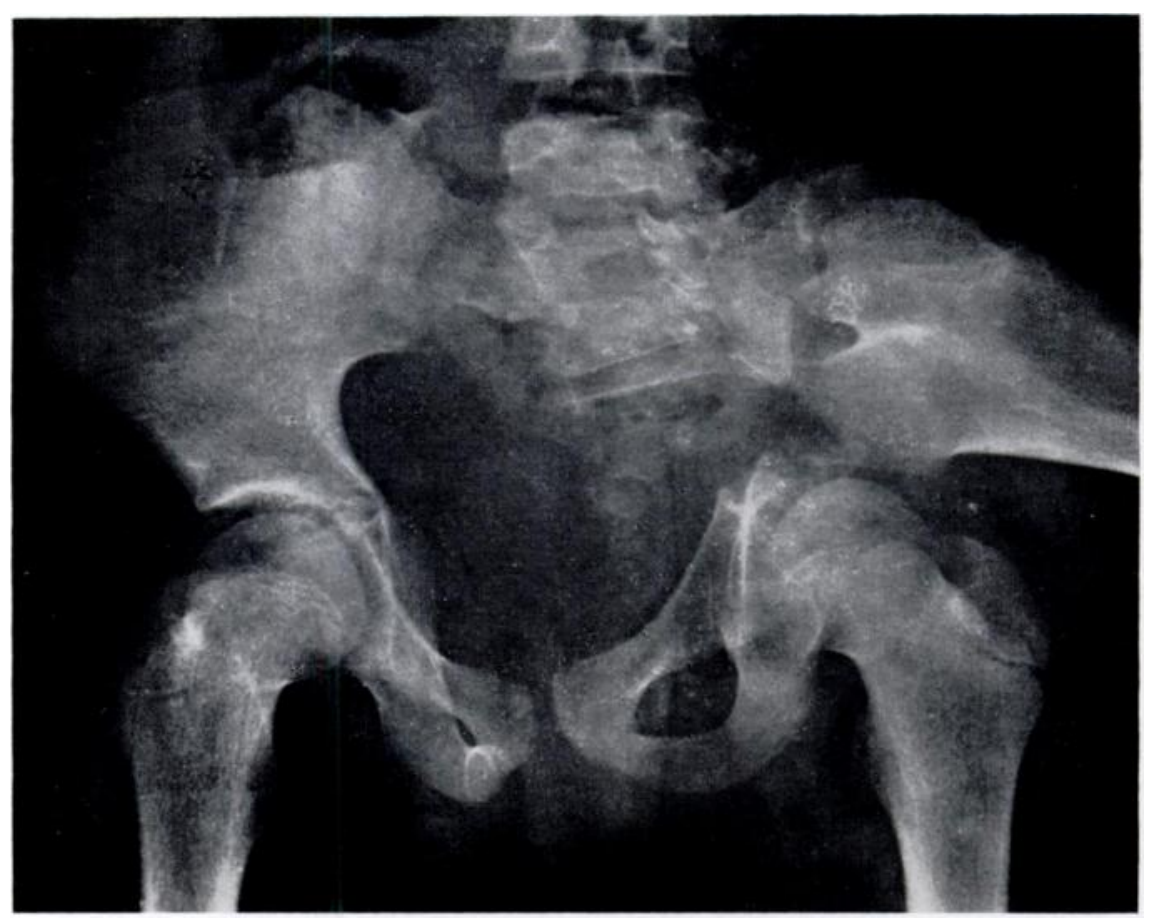

FiG. 1

Radiograph before reduction.

upon her. Shock was indicated by pallor, pulse of 130 per minute, and a blood pressure of 80 millimetres systolic and 50 millimetres diastolic. Haemoglobin was 50 per cent and the red blood cell count 2,710,000. Physical examination revealed marked swelling in the region of the left half of the pelvis, and a bony prominence was felt extending laterally. Abdominal distension was present. There was no evidence of neurological deficit. Radiographs showed fracture-dislocation of the left sacro-iliac joint: the entire ilium was separated through the tri-radiate cartilage and rotated posteriorly and laterally (Figs. 1 and 2). The femoral head was not dislocated, and Shenton's arc was intact. The promontory of the sacrum was fractured. Treatment and progress-After catheterisation, which showed no blood in the urine, and transfusion of one litre of matched blood, operation was performed (Dr Juan Gonzoles). No intra-abdominal injury was found. A large retroperitoneal haematoma was drained. It was not possible at this stage to manipulate the ilium back into position. 


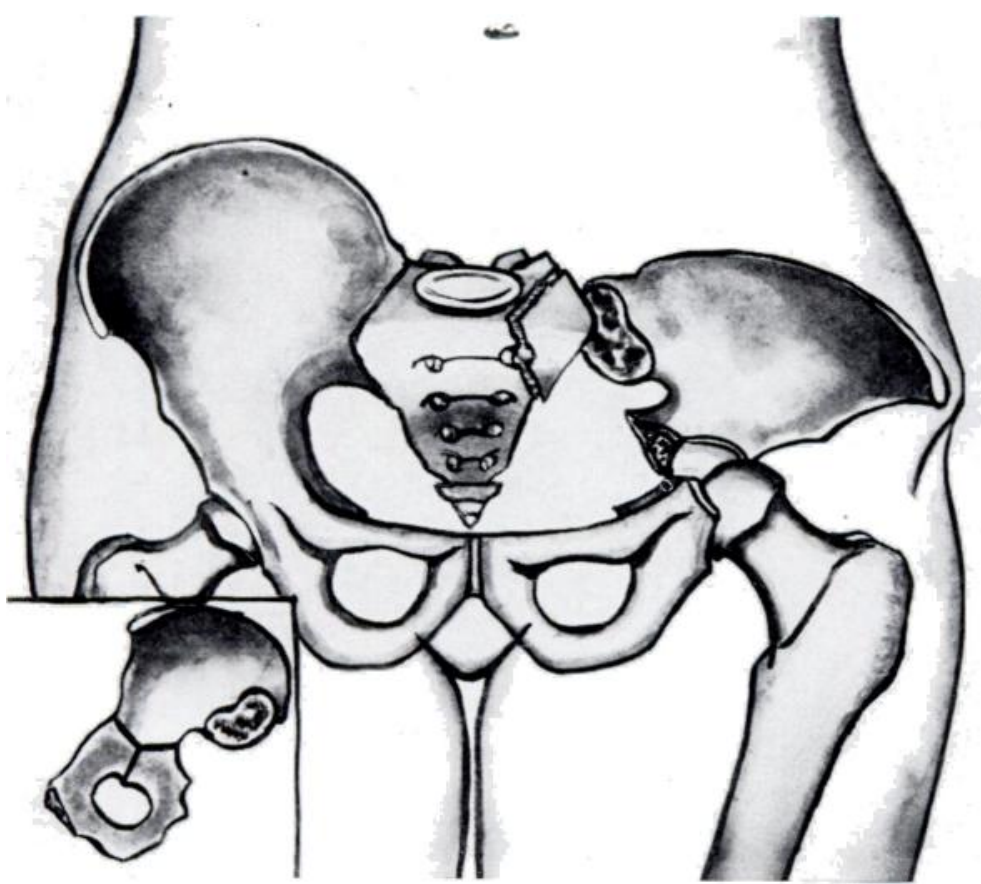

FIG. 2

Drawing to show the main features of the injury. Inset shows line of separation through tri-radiate cartilage.

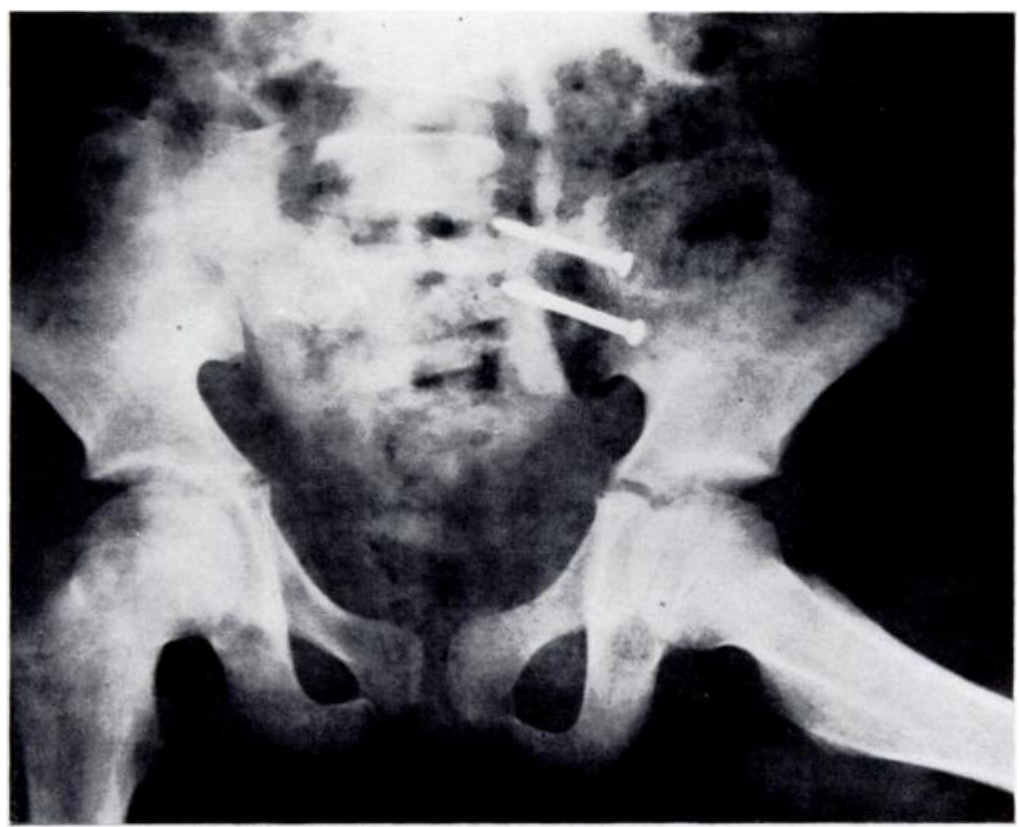

FIG. 3

Radiograph after open reduction and internal fixation. 
Four days later her condition permitted further operation to reduce the iliac displacement. Incision was made along the crest of the ilium, from the anterior superior spine to a point medial to the posterior superior spine. The gluteal muscles were reflected subperiosteally from the lateral aspect of the ilium, and the iliopsoas muscle from its pelvic surface. Muscular attachments were also freed from the anterior superior spine. This dissection permitted a full view of the dislocation of the sacro-iliac joint. The iliac disruption had occurred through the tri-radiate cartilage, so that the ilium hinged on the remaining ligaments of the sacro-iliac joint. It was then possible to rotate the ilium anteriorly and distally into its normal position. The reduction was maintained by two screws driven from the postero-lateral surface of the ilium across the sacro-iliac joint to engage the sacrum (Fig. 3). Thereafter a short double plaster spica was applied to protect the rather tenuous reduction. Progress was marred by the patient's premature removal from hospital. Pressure sores developed and later readmission for skin grafting was required. A year after the injury the girl was free from disability.

Comment-It is probable that this injury could occur only in the immature skeleton, before ossification of the tri-radiate cartilage. The force must have been applied to the anterior part of the ilium by the impact of rock while the pelvis lay in the supine position.

\section{SUMMARY}

A case of total dislocation of the ilium after disruption through the tri-radiate cartilage in a girl of thirteen years is described. No previous description of this injury has been found.

We wish to thank Care Medico and Dr Elio Melle of the Dominican Republic for the opportunity of studying this case, and Dr W. J. Hart of Winnipeg for help with the illustrations. 